\title{
Electrospun $\mathrm{ZnSnO}_{3} / \mathrm{ZnO}$ composite nanofibers and its air-sensitive properties
}

\section{Songao Dong ${ }^{\mathrm{a}, \mathrm{b}^{*}}$, Xiaoyun Jin ${ }^{\mathrm{b}}$, Junlin Wei ${ }^{\mathrm{b}}$, Hongyan $\mathrm{Wu}^{\mathrm{a}^{*}}$}

${ }^{a}$ Institute of Advanced Materials and Flexible Electronics (IAMFE), School of Chemistry and Materials Science,

Nanjing University of Information Science and Technology, Nanjing 210044, China

${ }^{b}$ Institute of Material Science and Engineering, Jiangsu University of Science and Technology, Zhenjiang 212003,

China

\begin{abstract}
In this work, a novel heterojunction based on $\mathrm{ZnSnO}_{3} / \mathrm{ZnO}$ nanofibers was prepared using electrospinning method. The crystal, structural and surface compositional properties of sample based on $\mathrm{ZnSnO}_{3}$ and $\mathrm{ZnSnO}_{3} / \mathrm{ZnO}$ composite nanofibers were investigated by X-ray diffractometer (XRD), Scanning electron microscope (SEM), X-ray photoelectron spectrometer (XPS) and Brunauer-Emmett-Teller (BET). Compared to pure $\mathrm{ZnSnO}_{3}$ nanofibers, the $\mathrm{ZnSnO}_{3} / \mathrm{ZnO}$ heterostructure nanofibers display high sensitivity and selectivity response with fast response towards ethanol gas at low operational temperature. The sensitivity response of sensor based on $\mathrm{ZnSnO}_{3} / \mathrm{ZnO}$ composite nanofibers were 19.6 towards $50 \mathrm{ppm}$ ethanol gas at $225^{\circ} \mathrm{C}$, which was about 1.5 times superior than that of pure $\mathrm{ZnSnO}_{3}$ nanofibers, which can be owed mainly to the presence of oxygen vacancies and the synergistic effect between $\mathrm{ZnSnO}_{3}$ and $\mathrm{ZnO}$.
\end{abstract}

Keywords: Electrospinning; $\mathrm{ZnSnO}_{3} / \mathrm{ZnO}$ nanofibers; Sensing performance; n-n heterojunction

* Corresponding author.

E-mail addresses: stdong@just.edu.cn (Songtao Dong); wuhy2009@nuist.edu.cn (Hongyan Wu) 


\section{Introduction}

In recent years, with the increasing demand for the detection of toxic gases, volatile organic compounds and clinical gas analysis, gas sensor research has become more and more extensive. High sensitivity, fast response, excellent selectivity and long-term stability are the basic parameters of a highly sensitive gas sensor [1]. Semiconductor metal oxide gas sensors have attracted much attention because of their advantages such as fast response, low cost, simple structure and good compatibility. Semiconductor metal oxide materials(e.g. NiO [2], $\mathrm{SnO}_{2}[3,4], \mathrm{ZnO}$ [5], $\mathrm{CuO}$ [6], etc.) are widely used for their high performance, cost effectiveness and excellent gas sensing properties, but these binary oxide materials operate at high temperatures, so the search for a sensing material with low operating temperature and high sensitivity has become the focus of current research.

At present, ternary transition metal oxides as new gas-sensitive materials have received widespread attention due to their excellent gas-sensitive properties, structural stability, especially their unique energy band structure and unique physical and chemical properties. However, due to insufficient exposure area and low electron transfer, many ternary metal oxides tend to show lower gas sensitivity [7]. Among the ternary tin-based metal oxides, $\mathrm{ZnSnO}_{3}$ is a typical perovskite structure oxide material with $\mathrm{Zn}$ at the A-site and $\mathrm{Sn}$ at the B-site. Compared to $\mathrm{ZnO}$ and $\mathrm{SnO}_{2}, \mathrm{ZnSnO}_{3}$ has been widely used in gas sensors for its high chemical sensitivity and excellent electrical properties [8]. The spatial arrangement of the atoms in the $\mathrm{ZnSnO}_{3}$ system is an octahedron. The special crystal structure of $\mathrm{ZnSnO}_{3}$ can have a lot of oxygen vacancies, provide more oxygen adsorption sites, can promote the reaction with reducing gases, thereby improving the gas sensitivity [8]. Many studies have focused on single component $\mathrm{ZnSnO}_{3}$ as a gas sensing material. Wang et al.[9] reported that the sensitivity response to $100 \mathrm{ppm}_{2} \mathrm{~S}$ of hollow, cubic-structured $\mathrm{ZnSnO}$ sample was up to 1418 at an optimum operating temperature of $335^{\circ} \mathrm{C} . \mathrm{ZnSnO}_{3}$ nanomicrospheres was prepared by hydrothermal method, which had high selectivity for n-butanol at $200^{\circ} \mathrm{C}[10]$. Wang and his team found that $\mathrm{ZnSnO}_{3}$ samples prepared by co-precipitation and heat treatment had a high sensitivity response to ethanol, reaching 147 [11]. Researchers have also prepared heterogeneous structures to improve gas sensing performance, such as $\mathrm{ZnSnO}_{3} / \mathrm{TiO}_{2}$ $\mathrm{SnO}_{2} / \mathrm{TiO}_{2}, \mathrm{WO}_{3} / \mathrm{SnO}_{2}$ and $\mathrm{ZnSnO} / \mathrm{ZnO}$ [12-15]. To further improve the gas-sensitive performance of $\mathrm{ZnSnO}_{3}$, Yu et al.compounded $\mathrm{ZnSnO}_{3}$ with $\mathrm{CuO}$ and found a sensitivity response to ethanol of up to 131 [16] . Zhang et al.[17] and Cheng et al.[18] reported that $\mathrm{ZnSnO}_{3}$ was compounded with $\mathrm{SnO}_{2}$, respectively, due to the excellent physical and chemical properties of both $\mathrm{SnO}_{2}$ and $\mathrm{ZnSnO}_{3}$, the gas-sensitive properties of the $\mathrm{SnO}_{2} / \mathrm{ZnSnO}_{3}$ composite were significantly improved compared to both $\mathrm{SnO}_{2}$ and $\mathrm{ZnSnO}_{3}$ materials. The cubic $\mathrm{ZnSnO}_{3} / \mathrm{ZnO}$ heterostructure showed a much improved response to $50 \mathrm{ppm}$ triethylamine compared to pure $\mathrm{ZnSnO}_{3}\left(\mathrm{R}_{\mathrm{a}} / \mathrm{R}_{\mathrm{g}}=21\right)$ [15]. These results indicate that heterostructures composed of $\mathrm{MO}_{\mathrm{x}}$ and $\mathrm{ZnSnO}_{3}$ have great potential for gas sensing applications.

Currently, researchers can prepare $\mathrm{ZnSnO}_{3}$ nanofibers with different morphologies (e.g. spherical, polyhedral, etc.)[19,20], but there are few reports on nanofiber samples with $\mathrm{ZnSnO}_{3}$-based heterojunctions. The electrospinning method allows to obtain nanofibrous materials with high specific surface area and different morphologies. Based on the above considerations, $\mathrm{ZnSnO}_{3}$ nanofibers and $\mathrm{ZnSnO}_{3} / \mathrm{ZnO}$ composite nanofibers were synthesised by electrospinning in this paper. The results of gas-sensitive performance of $\mathrm{ZnSnO}_{3}$ nanofibers and $\mathrm{ZnSnO}_{3} / \mathrm{ZnO}$ nanofibers showed that the $\mathrm{ZnSnO}_{3} / \mathrm{ZnO}$ nanofibers had a lower operating temperature $\left(225^{\circ} \mathrm{C}\right)$, a sensitivity response of 19.6 at $50 \mathrm{ppm}$ in ethanol atmosphere and better stability than $\mathrm{ZnSnO}_{3}$. The possible enhanced gas sensing mechanism was proposed.

\section{Experimental section}

\subsection{Material preparation}

A combination of electrospinning and calcination was used to prepare $\mathrm{ZnSnO}_{3} / \mathrm{ZnO}$ 
nanofibers. The experimental procedure was as follows: First, appropriate amounts of stannous chloride $\left(\mathrm{SnCl}_{2} \cdot 2 \mathrm{H}_{2} \mathrm{O}\right)$ and zinc chloride $\left(\mathrm{ZnCl}_{2}\right)$ were dissolved in a mixed solution of $8 \mathrm{~g} \mathrm{~N}, \mathrm{~N}$-dimethylformamide (DMF) and $12 \mathrm{~g}$ anhydrous ethanol under constant stirring so that the molar ratio of $\mathrm{Sn}^{4+}$ to $\mathrm{Zn}^{2+}$ was 1:1.2. Next, $2 \mathrm{~g}$ of PVP (average molecular weight of $1300000 \mathrm{~g} \mathrm{~mol}^{-1}$ ) was added and stirred thoroughly to finally obtain the precursor solution required for the electrospinning method. The electrospinning precursor solution was then loaded into a plastic syringe with a 22-gauge needle and the advance rate of the syringe pump was set at $0.4 \mathrm{~mL} \mathrm{~h}^{-1}$. A voltage of $15 \mathrm{kV}$ is applied between the needle and the collector, and a layer of aluminium foil is wrapped around the rotating receiver $20 \mathrm{~cm}$ from the needle to collect the fibres. The collected precursor fibers were calcined in air at $450{ }^{\circ} \mathrm{C}$ for $2 \mathrm{~h}$ to obtain $\mathrm{ZnSnO}_{3} / \mathrm{ZnO}$ nanofibers.

\subsection{Characterization}

The physical phases of the calcined samples were analysed by X-ray powder diffractometer (XRD, Bruker D8 Advance) using a copper target $\mathrm{K}_{\alpha}$ line with a scanning range of $20-60^{\circ}$ and a scanning speed of $6 \%$ min. The field emission scanning electron microscopy (Merlin Compact, Carl Zeiss, Germany) was used to characterize morphology of the samples. Thermogravimetric tests were carried out by a thermal analysis system (Diamond TG/DTA, Perkin Elmer S. A.) to determine the calcination temperature of the precursors, using samples weighing $4-6 \mathrm{mg}$ and heated to $600{ }^{\circ} \mathrm{C}$ at a heating rate of $15{ }^{\circ} \mathrm{C} / \mathrm{min}$. The elemental composition and valence states in the material were characterized using an X-ray photoelectron spectrometer (Thermo Scientific K-Alpha, XPS). Specific surface area of the prepared nanofibers by $\mathrm{N}_{2}$ adsorption/desorption test (BET, Micromeritics ASAP 2020).

\subsection{Gas-sensitive performance measurement}

A $200 \mathrm{mg}$ sample of $\mathrm{ZnSnO}_{3} / \mathrm{ZnO}$ nanofibers was mixed well with $0.2 \mathrm{~mL}$ of deionised water in an agate mortar and ground to a paste. The ground paste sample is then uniformly coated on the surface of the Ag-Pd forked finger electrode on an $\mathrm{Al}_{2} \mathrm{O}_{3}$ substrate and dried for a certain period of time to obtain the gas sensitive element required for the test. Before testing, the dried gas-sensitive elements are aged in air for $10 \mathrm{~h}$. The sensitivity response, operating temperature and stability of the preparations were tested on the CGS-1TP Intelligent Gas Sensitive Analysis System.

\section{Results and Discussion}

\subsection{Microstructure and morphology}

In order to determine the calcination temperature of the $\mathrm{ZnSnO}_{3}$ precursor obtained by electrospinning methods, TG tests were carried out on the $\mathrm{ZnSnO}_{3}$ precursor in an air atmosphere in the temperature range of $30-600{ }^{\circ} \mathrm{C}$ with a heating rate of $15{ }^{\circ} \mathrm{C} / \mathrm{min}$. The results are shown in Figure 1(a). The graph shows an $8 \mathrm{wt} \%$ drop in sample mass at $300{ }^{\circ} \mathrm{C}$. This is due to the evaporation of organic solvents and the evaporation of gases and moisture adsorbed on the surface of the sample. The sharp decrease in sample mass around $350{ }^{\circ} \mathrm{C}$ can be attributed to the decomposition of the precursor, while the significant drop in the curve around $400{ }^{\circ} \mathrm{C}$ can be attributed to the decomposition of PVP. In addition, no significant weight changes were observed above $450{ }^{\circ} \mathrm{C}$, which proves that all organic matter in the precursor decomposes at $450{ }^{\circ} \mathrm{C}$ and that calcination of the precursor at temperatures higher than $450{ }^{\circ} \mathrm{C}$ is sufficient. Figure 1 (b) shows the $\mathrm{XRD}$ results of the $\mathrm{ZnSnO}_{3} / \mathrm{ZnO}$ precursor after $2 \mathrm{~h}$ of calcination at $450{ }^{\circ} \mathrm{C}$. A comparison with the standard card (PDF No. 28-1486) shows that the XRD diffraction peaks at $2 \theta$ of $26.5^{\circ}, 33.7^{\circ}, 37.7^{\circ}, 51.6^{\circ}$ and $54.6^{\circ}$ correspond to the (012), (110), (015), (116), (018) and (214) crystal planes of $\mathrm{ZnSnO}_{3}$, respectively. The remaining XRD diffraction peaks were compared with the standard card (PDF No. 65-3411) and were found to correspond to (100), (101), (102) and (110) crystal planes at $2 \theta$ of $31.7^{\circ}, 36.3^{\circ}$, $47.5^{\circ}$ and $56.6^{\circ}$, respectively. That is, the XRD diffraction peak corresponding to the standard card (PDF No. 65-3411) is the diffraction peak of $\mathrm{ZnO}$. The results show that the $\mathrm{ZnSnO}_{3} / \mathrm{ZnO}$ 
precursors were successfully prepared after calcination in air at $450{ }^{\circ} \mathrm{C}$ for $2 \mathrm{~h}$.
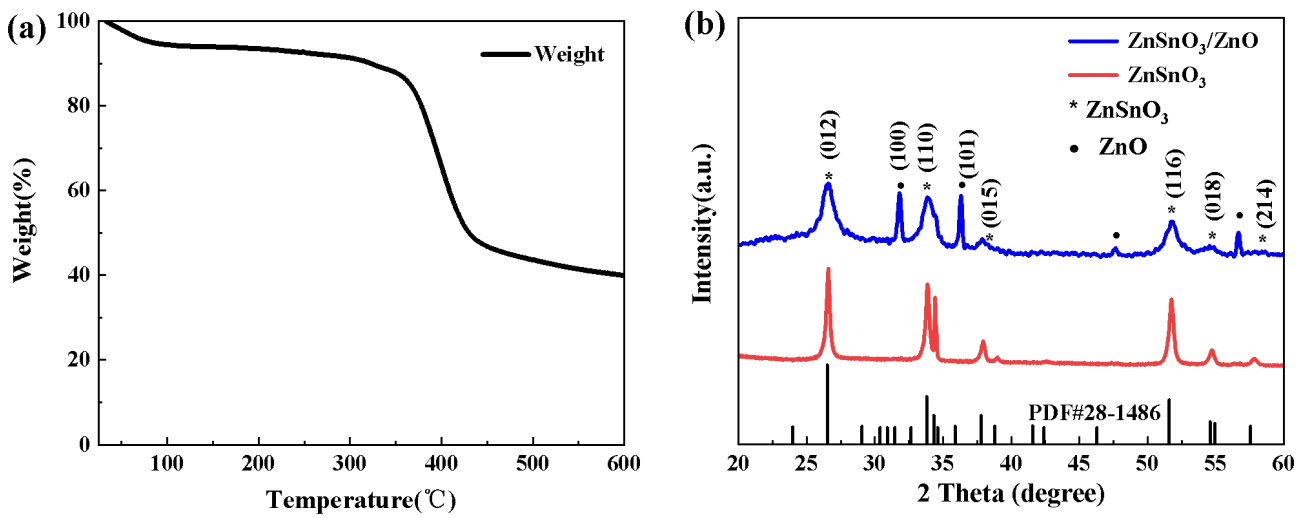

Figure 1 (a) TG test results of $\mathrm{ZnSnO}_{3}$ precursors; (b) $\mathrm{XRD}$ of $\mathrm{ZnSnO}_{3}$ and $\mathrm{ZnSnO} / \mathrm{ZnO}$ calcined at $450{ }^{\circ} \mathrm{C}$

Figure 2(a) and (b) shows the SEM results of $\mathrm{ZnSnO}_{3}$ samples prepared after calcination at $450{ }^{\circ} \mathrm{C}$ for $2 \mathrm{~h}$ in an air atmosphere. As can be seen in Figure 2(a), the $\mathrm{ZnSnO}_{3}$ sample after calcination at $450{ }^{\circ} \mathrm{C}$ for $2 \mathrm{~h}$ in an air atmosphere is coarse and uniformly fibrous, with no breakage of the continuous fibers. The average diameter of the $\mathrm{ZnSnO}_{3}$ sample is about 300 $400 \mathrm{~nm}$, as shown in Figure 2 (b). Figure 2(c) and (d) shows the SEM results of $\mathrm{ZnSnO}_{3} / \mathrm{ZnO}$ samples prepared after calcination at $450{ }^{\circ} \mathrm{C}$ for $2 \mathrm{~h}$ in air atmosphere. As can be seen in Figure 2(c), the $\mathrm{ZnSnO}_{3} / \mathrm{ZnO}$ sample exhibits uniformly coarse and fine fibers with no fracture in the fiber continuity. The average diameter of the $\mathrm{ZnSnO}_{3} / \mathrm{ZnO}$ nanofibers is even smaller, around $200 \mathrm{~nm}$, as shown in Figure 2(d). Due to the low calcination temperature of $450{ }^{\circ} \mathrm{C}$, the rate of gas production from the decomposition of pharmaceuticals is slow and the pressure difference between the interior and exterior of the fibers is not large, so no hollow structure is formed [21]. The above experiments show that the diameter of the $\mathrm{ZnSnO}_{3} / \mathrm{ZnO}$ nanofibers obtained by compounding $\mathrm{ZnSnO}_{3}$ with $\mathrm{ZnO}$ is significantly reduced compared to the $\mathrm{ZnSnO}_{3}$ nanofibre samples.The BET analysis shows that the specifc surface area of the $\mathrm{ZnSnO}_{3} / \mathrm{ZnO}$ nanofibers $\left(31.24 \mathrm{~m}^{2} \mathrm{~g}^{-1}\right)$ was substantially larger than that of pristine $\mathrm{ZnSnO}_{3}$ nanofibers $\left(20.15 \mathrm{~m}^{2} \mathrm{~g}^{-1}\right)$.

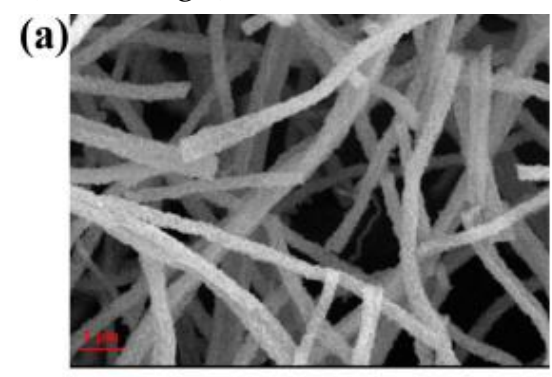

(b)

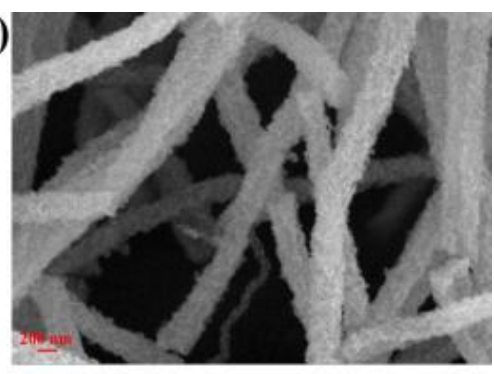

(c)

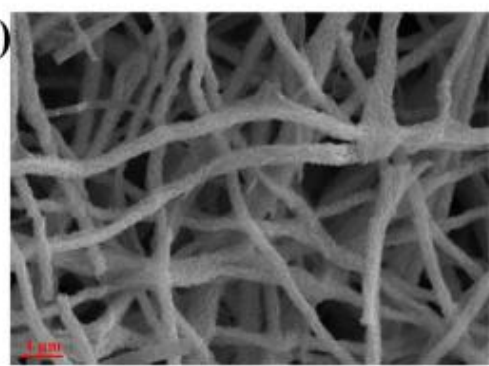

(d)

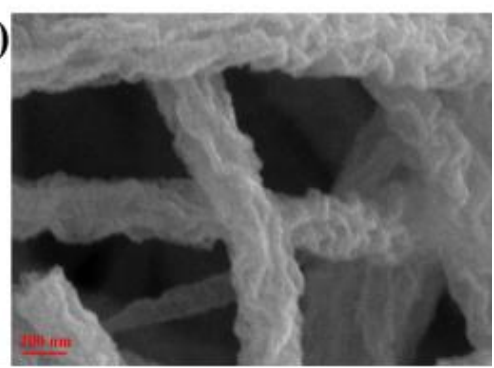

Figure 2 SEM images of $\mathrm{ZnSnO}_{3}$ and $\mathrm{ZnSnO}_{3} / \mathrm{ZnO}$ : (a) and (b) $\mathrm{ZnSnO}_{3}$; (c) and (d)

$\mathrm{ZnSnO}_{3} / \mathrm{ZnO}$

XPS are carried out to study the elemental composition and valence states in 
$\mathrm{ZnSnO}_{3} / \mathrm{ZnO}$, and the results are shown in Figure 3. Figure 3 (a) shows the full XPS spectrum of the $\mathrm{ZnSnO}_{3} / \mathrm{ZnO}$ nanofibers, from which it can be observed that the obtained $\mathrm{ZnSnO}_{3} / \mathrm{ZnO}$ nanofibers contain the elements $\mathrm{Zn}, \mathrm{Sn}, \mathrm{C}$ and $\mathrm{O}$. The peak at $284.8 \mathrm{eV}$ corresponds to the spin-orbit peak of $C$ 1s.The broad XPS spectrums of the Zn-2p range, Sn-3d and O-1s range are shown in Fig.3(b) and (d). In case of $Z n-2 p$ spectrum, the $Z n-2 p$ peak can be distributed into two signals as shown in Fig. 3(b). Zn-2 $p_{3 / 2}$ and $Z n-2 p_{1 / 2}$ signals are focused at $1021.1 \mathrm{eV}$ and $1044.1 \mathrm{eV}$, respectively, which indicates that the chemical valence of $\mathrm{Zn}$ in the system is +2 [22]. As shown in Fig. 3(c), the two peaks at 486.8 and $495.1 \mathrm{eV}$ correspond to the Sn $3 d_{5 / 2}$ and Sn $3 d_{3 / 2}$ spin-orbit peaks, respectively. The bimodal spin orbit shows a split value of approximately $8.3 \mathrm{eV}$, indicating the presence of $\mathrm{Sn}^{4+}$ cations [23]. The $\mathrm{O}_{1 \mathrm{~s}}$ spectrum of $\mathrm{ZnSnO}_{3}$ and $\mathrm{ZnSnO}_{3} / \mathrm{ZnO}$ is illustrated in Fig. 3(d) and (e), which is deconvolved into three characteristic peaks by Gaussian fitting[16,24]. The three fitting peaks are attributed to three important oxygen species [25], denoted as $\mathrm{O}_{\mathrm{L}}, \mathrm{O}_{\mathrm{V}}, \mathrm{O}_{\mathrm{C}}$, respectively, corresponding to $\mathrm{O}^{2-}$ species in the crystal lattice, VOs and chemically adsorbed or dissociated oxygen species, respectively [26]. The three characteristic peaks of $\mathrm{O} 1 \mathrm{~s} \mathrm{in} \mathrm{ZnSnO}_{3}$ nanofibers are located at $530.06 \mathrm{eV}, 531.65 \mathrm{eV}$ and $533.13 \mathrm{eV}$, while the characteristic peaks of $\mathrm{O} 1 \mathrm{~s}$ in $\mathrm{ZnSnO}_{3} / \mathrm{ZnO}$ nanofibers are located at $529.99 \mathrm{eV}, 531.33 \mathrm{eV}$, and $532.27 \mathrm{eV}$, which can be corresponded to the $\mathrm{O}_{\mathrm{L}}, \mathrm{O}_{V}, \mathrm{O}_{\mathrm{C}}$ species, respectively[17,27]. It must be pointed out that the gas sensitivity characteristics may be highly dependent on the type of $\mathrm{VO}$ present on the semiconductor surface [28]. Fig. 4(f) shows that the relative percentage of each oxygen species in $\mathrm{ZnSnO}_{3}$ and $\mathrm{ZnSnO}_{3} / \mathrm{ZnO}$ nanofibers. The proportion of oxygen species in obtained $\mathrm{ZnSnO}_{3}$ and $\mathrm{ZnSnO}_{3} / \mathrm{ZnO}$ nanofibers are shown in the table 1. The results of Fig.4(f) and table 1 are clear that compared with the percentage of $\mathrm{Ov}$ of $\mathrm{ZnSnO}_{3}$ nanofibers, that of $\mathrm{ZnSnO}_{3} / \mathrm{ZnO}$ nanofibers substantially increases.
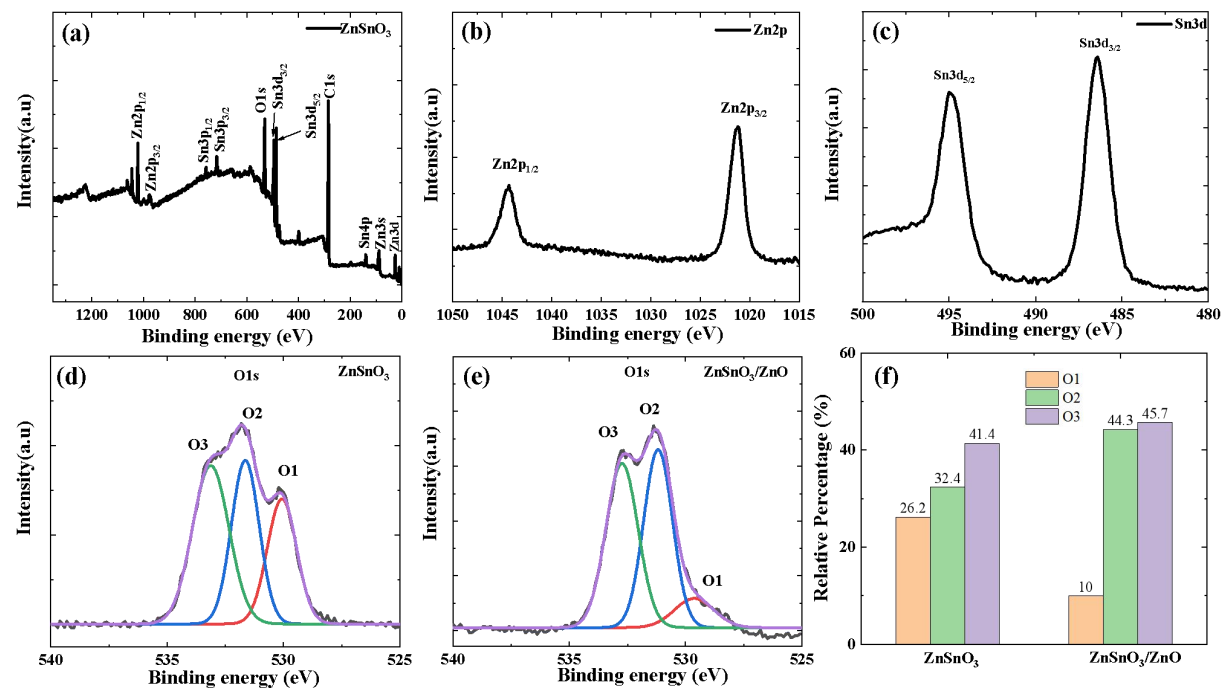

Fig.3 XPS spectra of $\mathrm{ZnSnO}_{3} / \mathrm{ZnO}$ nanofibers: (a) a survey spectrum, high resolution spectra for (b) $\mathrm{Zn} \mathrm{2p}$, (c) Sn3d, (d) O1s (of $\mathrm{ZnSnO}_{3}$ ), (e) O1s (of $\mathrm{ZnSnO}_{3} / \mathrm{ZnO}$ ), (f) fitting results of O 1s XPS spectra of $\mathrm{ZnSnO}_{3}$ and $\mathrm{ZnO} / \mathrm{ZnSnO}_{3}$.

Table 1 The proportion of oxygen species in obtained $\mathrm{ZnSnO}_{3}$ and $\mathrm{ZnO} / \mathrm{ZnSnO}_{3}$ nanofibers.

\begin{tabular}{|c|c|c|c|}
\hline Sample & $\mathrm{O}^{2-(\%)}$ & $\mathrm{O}^{-}(\%)$ & $\mathrm{O}_{2-(\%)}$ \\
\hline $\mathrm{ZnSnO}_{3}$ & $26.2 \%$ & $32.4 \%$ & $41.4 \%$ \\
\hline $\mathrm{ZnO} / \mathrm{ZnSnO}_{3}$ & $10 \%$ & $44.3 \%$ & $45.7 \%$ \\
\hline
\end{tabular}




\subsection{Gas-sensitive properties of $\mathrm{ZnSnO}_{3} / \mathrm{ZnO}$ nanofibers}

It is well known that changes in operating temperature can highly influence the gas sensing characteristics of sensing materials. To verify this, the response of $\mathrm{ZnSnO}_{3}$ samples and $\mathrm{ZnSnO}_{3} / \mathrm{ZnO}$ composite nanofibers toward $50 \mathrm{ppm}$ ethanol gas are tested at different temperatures and the results are shown in Figure 4. Figure 4(a) show that the response of the $\mathrm{ZnSnO}_{3}$ sample increases with increasing temperature untill the temperature rises to $300{ }^{\circ} \mathrm{C}$, when the response is maximum at 13.4. Then the temperature continues to increase and the response decreases instead. Figure 4(b) shows the sensitivity response of $\mathrm{ZnSnO}_{3} / \mathrm{ZnO}$ samples towards $50 \mathrm{ppm}$ ethanol gas at different temperatures. From the graph it can be concluded that the optimum working temperature for the $\mathrm{ZnSnO}_{3} / \mathrm{ZnO}$ sample is $225^{\circ} \mathrm{C}$ and the sensitivity response for the $\mathrm{ZnSnO}_{3} / \mathrm{ZnO}$ sample is 19.6. The optimum operating temperature of the $\mathrm{ZnSnO}_{3} / \mathrm{ZnO}$ sample is significantly lower than that of the $\mathrm{ZnSnO}_{3}$ sample. The sensitivity response has also been improved, with a $46.3 \%$ increase in sensitivity response.
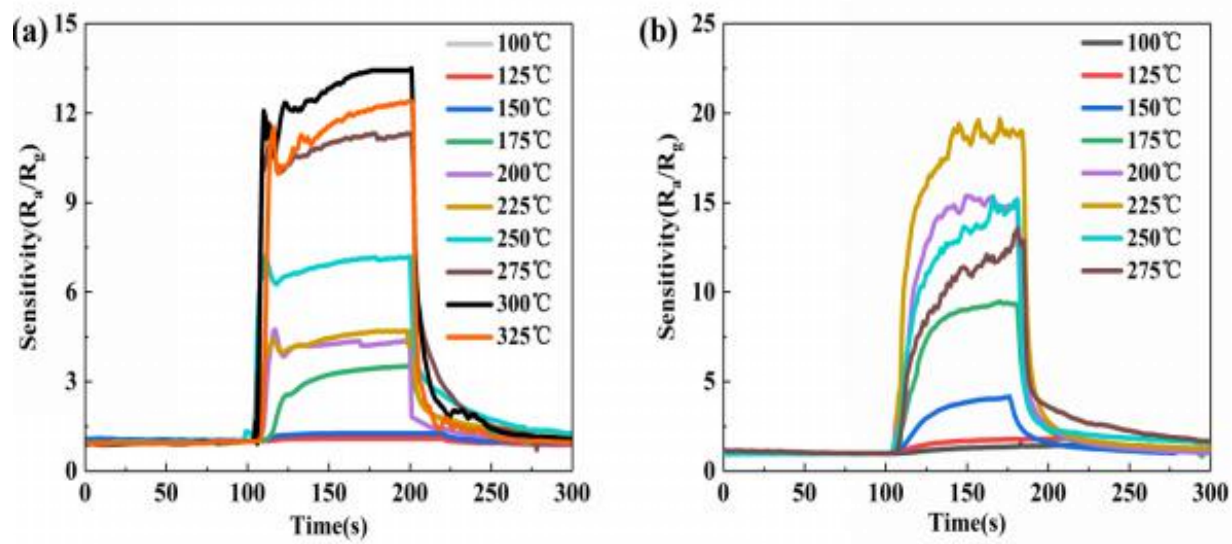

Fig.4 Sensitivity of $\mathrm{ZnSnO}_{3}$ and $\mathrm{ZnSnO}_{3} / \mathrm{ZnO}$ towards 50 ppm ethanol at different temperatures: (a) $\mathrm{ZnSnO}_{3}$; (b) $\mathrm{ZnSnO}_{3} / \mathrm{ZnO}$

To further investigate the gas-sensitive performance of the $\mathrm{ZnSnO}_{3} / \mathrm{ZnO}$ samples, the response of $\mathrm{ZnSnO}_{3}$ and $\mathrm{ZnSnO}_{3} / \mathrm{ZnO}$ samples to different concentrations of ethanol and the stability of the response to $50 \mathrm{ppm}$ ethanol were tested at the optimum operating temperature, respectively, and the results are shown in Figure 5. As seen in Fig. 5(a), the response of $\mathrm{ZnSnO}_{3} / \mathrm{ZnO}$ increases with increasing ethanol concentration due to the fact that with increasing ethanol concentration, more ethanol molecules react with the oxygen ions adsorbed on the surface of the material, resulting in a higher carrier concentration and thus a subsequent increase in the response of the material. Figure 5(b) show that the response of the $\mathrm{ZnSnO}_{3} / \mathrm{ZnO}$ composite samples increased with increasing ethanol concentration, while the response of the $\mathrm{ZnSnO}_{3} / \mathrm{ZnO}$ samples was higher than that of the $\mathrm{ZnSnO}_{3}$ samples at the same concentration of ethanol. Figure 5 (c) and (d) show the stability of the $\mathrm{ZnSnO}_{3}$ sample and the $\mathrm{ZnSnO}_{3} / \mathrm{ZnO}$ sample under ethanol atmosphere at $50 \mathrm{ppm}$, respectively. As can be seen from the graphs, the $\mathrm{ZnSnO}_{3}$ and $\mathrm{ZnSnO}_{3} / \mathrm{ZnO}$ samples showed no significant fluctuations in response after six repeated exposures to ethanol at $50 \mathrm{ppm}$, indicating that both the $\mathrm{ZnSnO}_{3}$ and $\mathrm{ZnSnO}_{3} / \mathrm{ZnO}$ samples have good stability. The above experimental results show that the $\mathrm{ZnSnO}_{3} / \mathrm{ZnO}$ sample has a lower working temperature, higher response and better stability for ethanol atmosphere than the $\mathrm{ZnSnO}_{3}$ sample. 

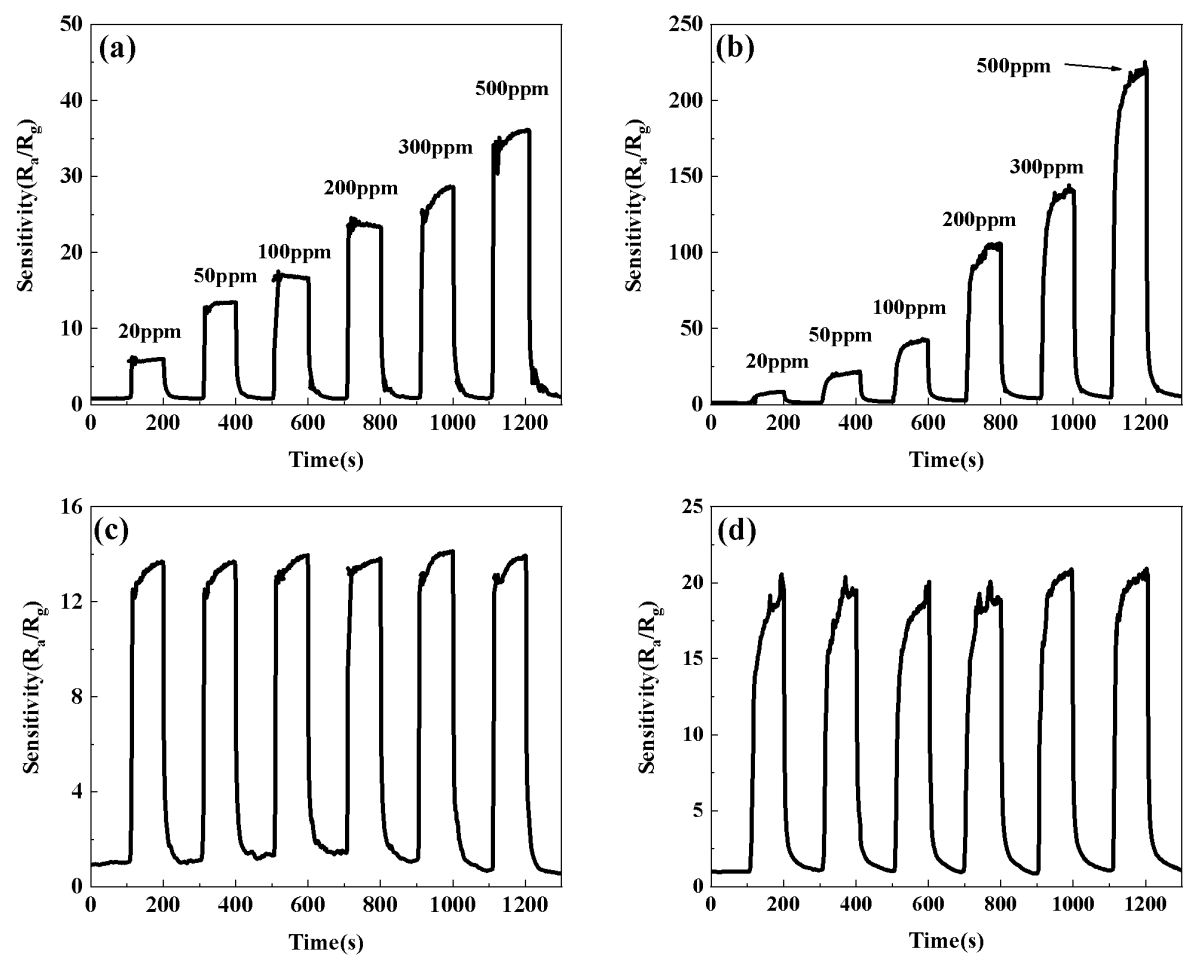

Fig.5 Sensitivity of $\mathrm{ZnSnO}_{3}$ and $\mathrm{ZnSnO}_{3} / \mathrm{ZnO}$ to different concentrations of ethanol at the optimal working temperature: (a) $\mathrm{ZnSnO}_{3}$; (b) $\mathrm{ZnSnO}_{3} / \mathrm{ZnO}$; the best Stability of sensitivity to $50 \mathrm{ppm}$ ethanol at working temperature: (c) $\mathrm{ZnSnO}_{3} ;$ (d) $\mathrm{ZnSnO}_{3} / \mathrm{ZnO}$

\subsection{Gas-sensing mechanism}

The sensing mechanism based on metal oxide semiconductor gas sensor is the changed resistance caused by the adsorption and desorption of the target gas molecules on the surface of sensitive materials, which depends mainly on the concentration and mobility of the charge. Therefore, the gas-sensitive mechanism of $\mathrm{ZnSnO}_{3}$ and $\mathrm{ZnSnO}_{3} / \mathrm{ZnO}$ composite nanofibers can be understood simply as a surface-controlled mechanism. The change in resistance depends on the type and amount of oxygen chemisorbed on the surface. In ambient air, the resistance of $\mathrm{ZnSnO}_{3}$ and $\mathrm{ZnSnO}_{3} / \mathrm{ZnO}$ composite nanofibers is mainly controlled by the concentration of adsorbed oxygen $\left(\mathrm{O}^{-}\right.$and $\left.\mathrm{O}^{2-}\right)$. The variation in response for $\mathrm{ZnSnO}_{3}$ nanofibers is mainly related to the adsorption-desorption reaction of ethanol gas on the surface of $\mathrm{ZnSnO}_{3}$ samples. $\mathrm{ZnSnO}_{3}$ is a typical N-type semiconductor material, when it is in the air oxygen molecules adsorbed on the surface of $\mathrm{ZnSnO}_{3}$ and gain electrons and thus convert into oxygen ions. When a certain amount of oxygen ions accumulated on the material surface reaches equilibrium, an electron depletion layer is formed on the material surface, which reduces the carrier concentration of the material system and in turn leads to an increase in the material resistance. However, when $\mathrm{ZnSnO}_{3}$ is placed in an ethanol atmosphere, the ethanol molecules will react with oxygen ions, releasing a large number of electrons and causing the resistance of the material to drop, the equation for the above process reaction is as follows[29]:

$$
\begin{aligned}
& \left.\mathrm{O}_{2} \text { (gas }\right) \leftrightarrow \mathrm{O}_{2} \text { (ads) } \quad \mathrm{O}_{2}+e^{-} \rightarrow \mathrm{O}^{-}, \mathrm{O}_{2}^{-}, \mathrm{O}^{2-} \\
& \mathrm{C}_{2} \mathrm{H}_{5} \mathrm{OH}+6 \mathrm{O}^{2-}(\text { ads }) \leftrightarrow 2 \mathrm{CO}_{2}+3 \mathrm{H}_{2} \mathrm{O}+12 e^{-}
\end{aligned}
$$

According to ref [15], since both $\mathrm{ZnSnO}_{3}$ and $\mathrm{ZnO}$ are N-type semiconductor materials, when $\mathrm{ZnO}$ is successfully compounded with $\mathrm{ZnSnO}_{3}$ to form a homotypic heterojunction (i.e. $\mathrm{N}-\mathrm{N}$ junction), this $\mathrm{N}-\mathrm{N}$ junction is a key factor in improving the ethanol gas sensitivity 
between $\mathrm{ZnSnO}_{3}$ and $\mathrm{ZnO}$. Differences in the Fermi energy levels of two connected semiconductor compounds. The transfer of electrons from higher energy states to lower energy states until equilibrium is reached at the Fermi energy level, resulting in the formation of a depletion layer in the interface region. In contrast to $\mathrm{ZnSnO}_{3}$, the electrons on the $\mathrm{ZnSnO}_{3}$ conduction band in the $\mathrm{ZnSnO}_{3} / \mathrm{ZnO}$ sample are transferred to the $\mathrm{ZnO}$ conduction band to be trapped by oxygen molecules, resulting in the formation of a large number of oxygen anions. At the same time, the electron depletion layer appears near the surface of $\mathrm{ZnSnO}_{3} / \mathrm{ZnO}$, which is an important component of the gas sensing process. In the air environment, the increased height of the potential barrier of the $\mathrm{ZnSnO}_{3} / \mathrm{ZnO}$ heterostructured composite makes electron transfer more difficult, which also leads to a significant increase in sensor resistance $\left(\mathrm{R}_{\mathrm{a}}\right)$. In an ethanol environment, the reaction of ethanol molecules with oxygen ions releases electrons back into the $\mathrm{ZnSnO}_{3} / \mathrm{ZnO}$ heterojunction, resulting in an increase in electron concentration. This significantly reduces the potential barrier height of $\mathrm{ZnSnO}_{3}$ and $\mathrm{ZnO}$, significantly reducing the sensor resistance $\left(\mathrm{R}_{\mathrm{g}}\right)$. The analysis of the above gas-sensitive properties revealed that the heterogeneous structure of the $\mathrm{ZnSnO}_{3} / \mathrm{ZnO}$ composites enhanced electron transport and enabled effective separation of electrons and holes compared to the $\mathrm{ZnSnO}_{3}$ nanofibers material.

Compared to $\mathrm{ZnSnO}_{3}$ nanofibers, $\mathrm{ZnSnO}_{3} / \mathrm{ZnO}$ composite nanofibers have a larger VOs of $44.3 \%$, almost 1.5 times that of $\mathrm{ZnSnO}_{3}$ nanofibers, which is conducive to improve the sensitivity characteristics of gas-sensitive materials[30]. It is also suggested that in the "chemical sensitization" mechanism established by the spillover effect, $\mathrm{ZnO}$ plays an important role in activating the dissociation rate of molecular oxygen[31].

\section{Conclusion}

In conclusion, $\mathrm{ZnSnO}_{3}$ nanofibers and $\mathrm{ZnSnO}_{3} / \mathrm{ZnO}$ nanofibers were successfully prepared using a simple electrospinning method. The average diameter of the $\mathrm{ZnSnO}_{3} / \mathrm{ZnO}$ composite nanofibers is approximately $200 \mathrm{~nm}$. Compared to $\mathrm{ZnSnO}_{3}$ nanofibers, $\mathrm{ZnSnO}_{3} / \mathrm{ZnO}$ nanofibers have a lower operating temperature $\left(225^{\circ} \mathrm{C}\right)$, higher sensitivity $(19.6)$ and better stability in an ethanol atmosphere, which can be owed mainly to the presence of oxygen vacancies and the synergistic effect between $\mathrm{ZnSnO}_{3}$ and $\mathrm{ZnO}$. The results confirmed that $\mathrm{ZnSnO}_{3} / \mathrm{ZnO}$ nanofibers could have an outstanding potential candidate for ethanol detection.

Author Contributions: Conceptualizatin, Xiaoyun Jin; data curation, Junlin Wei; writing - original draft preparation, Songao Dong; writing-review and editing, Hongyan Wu. All authors have read and agreed to the published version of the manuscript.

Funding: This research received no external funding.

Institutional Review Board Statement: Not applicable.

Informed Consent Statement: Not applicable.

Data Availability Statement: The data used to support the findings of this study are available from the corresponding author upon request.

Acknowledgments: The authors acknowledge fnancial support from the National Natural Science Foundation of China (51702132). Song-Tao Dong acknowledges the open project of the National Laboratory of Solid State Microstructures at Nanjing University. Jun-Lin Wei acknowledges financial support from the Postgraduate Research \& Practice Innovation Program of Jiangsu Province (Grant No. KYCX20_3132).

Conflicts of Interest: The authors declare no conflict of interest. 


\section{References}

1. J. Ma, X. Xiao, Y. Zou, Y. Ren, X. Zhou, X.Yang, X. Cheng, Y. Deng, A general and straightforward route to noble metal-decorated mesoporous transition-metal oxides with enhanced gas sensing performance, Adv. Funct. Mater. 2019, 15, e1904240.

2. M. M. Gomaa, M. H. Sayed, V. L. Patil, M. Boshta, P. S. Patil. Gas sensing performance of sprayed $\mathrm{NiO}$ thin films toward $\mathrm{NO}_{2}$ gas, J. Alloys Compd. 2021, 885, 160908.

3. Y. Z. Wang,Y. Zeng, L. O. Wang, Z. Lou, L. Qiao, H. W. Tian, W. T. Zheng, Ultrathin nanorod-assembled $\mathrm{SnO}_{2}$ hollow cubes for high sensitive n-butanol detection, Sensor. Actuat. B-Chem. 2019, 283, 693-704.

4. X. Y. Kou, N. Xie, F. Chen, T. S. Wang, L. L. Guo, C. Wang, Q. J. Wang, J. Ma, Y. F. Sun. H, Zhang, G, Y, Lu. Superior acetone gas sensor based on electrospun $\mathrm{SnO}_{2}$ nanofibers by $\mathrm{Rh}$ doping, Sensor. Actuat. B-Chem. 2018, 25, 6861-869.

5. J. H. Kim, A. Mirzaei, H. W. Kim, S. S. Kim, Low voltage driven sensors based on ZnO nanowires for room temperature detection of $\mathrm{NO}_{2}$ and $\mathrm{CO}$ gases, ACS Appl. Mater. Interfaces 2019,11( 27), 24172-24183.

6. Wangchang Geng, Zhiyan Ma, Jianhua Yang, Libing Duan, Feng Li, Qiuyu Zhang. Pore size dependent acetic acid gas sensing performance of mesoporous $\mathrm{CuO}$, Sensor. Actuat. B-Chem. 2021,334, 129639.

7. K. Jain. R. P, Pant. S.T. Lakshmi-kumar, Effect of Ni doping on thick film $\mathrm{SnO}_{2}$ gas sensor, Sensor. Actuat. B-Chem. 2006, 113, 823-829.

8. Y. Yin,Y. Shen, P. Zhou, R. Lu, A. Li, S. Zhao,W. Liu, D. Wei, K.Wei, Fabrication characterization and n-propanol sensing properties of perovskite-type $\mathrm{ZnSnO}_{3}$ nanospheres based gas sensor, Appl. Surf. Sci. 2020, 509, 145335.

9. Z. Y. Wang, J. Y. Miao, H. X. Zhang, D. Wang, J. B. Sun. Hollow cubic $\mathrm{ZnSnO}_{3}$ with abundant oxygen vacancies for $\mathrm{H}_{2} \mathrm{~S}$ gas sensing. J. Hazard. Mater., 2020, 391: 122226.

10. G. Q. Feng, Y. H. Che, C. W. Song, J. K. Xiao, X. F. Fan, S. Sun, G. H. Huang, Y. C. Ma Morphology-controlled synthesis of $\mathrm{ZnSnO}_{3}$ hollow spheres and their n-butanol gas-sensing performance. Ceram. Int., 2021, 47: 2471-2482.

11. X. Y. Wang, X. T. Zhu, T. Tao, B. X. Leng, W. Xu, L. H. Mao, Structural inheritance and change from $\mathrm{ZnSn}(\mathrm{OH})_{6}$ to $\mathrm{ZnSnO}_{3}$ compounds used for ethanol sensors: Effects of oxygen vacancies, temperature and UV on gas-sensing properties. J. Alloys Compd. 2020, 829: 154445. 12. X.Wang, Y. Liu, B. Ding, H. Li, X. Zhu, M. Xia, Influence of the addition of nano- $\mathrm{TiO}_{2}$ and $\mathrm{ZnO}$ on the sensing performance of micro- $\mathrm{ZnSnO}_{3}$ ethanol sensors under UV illumination, Sensor. Actuat. B-Chem. 2018, 276, 211-221.

13. H. T. Xun, Z. B. Zhang, A. H. Yu, J. X. Yi, Remarkably enhanced hydrogen sensing of highly-ordered $\mathrm{SnO}_{2}$ decorated $\mathrm{TiO}_{2}$ nanotubes, Sensor. Actuat. B-Chem. 2018, 273, 983-990.

14. S. F. Shao, X. Chen, Y. Y. Chen, M. Lai, L. S. Che, Ultrasensitive and highly selective detection of acetone based on $\mathrm{Au} @ \mathrm{WO}_{3}-\mathrm{SnO}_{2}$ corrugated nanofibers, Appl. Surf. Sci. 2019, 473, 902-911.

15. Y. Yan, J. Y. Liu, H. S. Zhang, D. L. Song, J. Q. Li, P. P. Yang, M. L. Zhang, J. Wang, One-pot synthesis of cubic $\mathrm{ZnSnO}_{3} / \mathrm{ZnO}$ heterostructure composite and enhanced gas-sensing performance. J. Alloys. Compd. 2019, 780,193-201.

16. S. W. Yu, X. H. Jia, J. Yang, S. Z. Wang, Y. Li, H. J. Song, Highly sensitive ethanol gas sensor based on $\mathrm{CuO} / \mathrm{ZnSnO}_{3}$ heterojunction composites. Mater. Lett., 2021, 291: 129531.

17. J. T. Zhang, X. H. Jia, D. D. Lian, J. Yang, S. Z. Wang, Y. Li, H. J. Song, Enhanced selective acetone gas sensing performance by fabricating $\mathrm{ZnSnO}_{3} / \mathrm{SnO}_{2}$ concave microcube. Appl. Surf. Sci., 2021, 542: 148555.

18. Pengtei Cheng, Li Lv, Yinglin Wang, Bao Zhang, Yue Zhang, Yaoqiong Zhang, Zhaohui Lei, Luping $\mathrm{Xu} . \mathrm{SnO}_{2} / \mathrm{ZnSnO}_{3}$ double-shelled hollow microspheres based high-performance acetone gas sensor. Sensor. Actuat. B-Chem., 2021, 332: 129212.

19. Y Chen, L Yu, Q Li, T. Wang. An evolution from 3D face-centered-cubic $\mathrm{ZnSnO}_{3}$ nanocubes to 2D orthorhombic $\mathrm{ZnSnO}_{3}$ nanosheets with excellent gas sensing performance. Nanotechnology, 2012, 23(41): 415501.

20. D. Zhang, Y. Q. Zhang, Y. Fan, N. Luo, J. Xu. Micro-spherical $\mathrm{ZnSnO}_{3}$ material prepared 
by microwave-assisted method and its ethanol sensing properties. Chinese Chem. Lett., 2020, 31(8): 2087-2090.

21. Linlin Li, Shengjie Peng, Jin Wang, Yan Ling Cheah, Peifen Teh, Yahwen Ko, Chuiling Wong, and Madhavi Srinivasan. Facile Approach to Prepare Porous $\mathrm{CaSnO}_{3}$ Nanotubes via a Single Spinneret Electrospinning Technique as Anodes for Lithium Ion Batteries. Acs Appl. Mater. Inter., 2012, 4(11): 6005

22. Y. L. Qin, F. F. Zhang, X. C. Du, G. Huang, Y. C. Liu, L. M. Wang. Controllable synthesis of cube-like $\mathrm{ZnSnO}_{3} @ \mathrm{TiO}_{2}$ nanostructures as lithium ion battery anodes. J. Mater. Chem. A, 2015, 3(6): 2985-2990

23. J. F. Duan, S. C. Hou, S. G. Chen, H. G. Duan. Synthesis of amorphous $\mathrm{ZnSnO}_{3}$ hollow nanoboxes and their lithium storage properties. Mater. Lett., 2014, 122: 261-264

24. Oiong Chen, Yuhua Wang, Mingxiao Wang, Shuyi Ma,Peiyu Wang, Guoheng Zhang, Wanjun Chen, Haiyan Jiao, Liwei Liu, Xiaoli $\mathrm{Xu}$, Enhanced acetone sensor based on $\mathrm{Au}$ functionalized In-doped $\mathrm{ZnSnO}_{3}$ nanofibers synthesized by electrospinning method. J. Colloid Interf. Sci., 2019, 543, 285-299

25. D. Lian. B. Shi, R. Dai. X. H. Jia, X. Y. Wu.Synthesis and enhanced acetone gas-sensing performance of $\mathrm{ZnSnO}_{3} / \mathrm{SnO}_{2}$ hollow urchin nanostructures, J. Nanopart. Res. 2017,19, 401. 26. J. Y. Liu,T. S. Wang, B. Q. Wang, P. Sun, Q. Y. Yang, X. S. Liang, H. W. Song, G. Y. Lu, Highly sensitive and low detection limit of ethanol gas sensor based on hollow $\mathrm{ZnO} / \mathrm{SnO}_{2}$ spheres composite material. Sensor. Actuat. B-Chem. 2017, 245, 551-559.

27. S. L. Bai, Y. Tian,Y. H. Zhao, H. Fu, P. G. Tang, R X. Luo, D. Q. Li, A F. Chen, C. C. Liu, Construction of $\mathrm{NiO} @ \mathrm{ZnSnO}_{3}$ hierarchical microspheres decorated with $\mathrm{NiO}$ nanosheets for formaldehyde sensing, Sensor. Actuat. B-Chem. 2018, 259, 908-916.

28. M. A. Hashem, S. Akbar, P. Morris, Role of oxygen vacancies in nanostructured metal-oxide gas sensors:a review, Sensor. Actuat. B-Chem. 2019, 301,126845

29. Y. Zeng, Y. F. Bing, C. Liu, W. T. Zhang, G. T. Zou. Self-assembly of hierarchical $\mathrm{ZnSnO}_{3}-\mathrm{SnO}_{2}$ nanoflakes and their gas sensing properties. T. Nonferr. Metal. Soc., 2012, 22(10): 2451-2458

30. H. M. Gong, C. H. Zhao, G. Q. Niu, W. Zhang, F. Wang, Construction of 1D/2D $\alpha-\mathrm{Fe}_{2} \mathrm{O}_{3} / \mathrm{SnO}_{2}$ hybrid nanoarrays for sub-ppm acetone detection, Research 2020, 1, 304-314

31. L. Xiao, S. M. Shu, S. T. Liu, A facile synthesis of Pd-doped $\mathrm{SnO}_{2}$ hollow microcubes with enhanced sensing performance, Sensor. Actuat. B-Chem. 2015, 221,120-126. 